\title{
Efektivitas Terapi Zikir Istighfar untuk Mengurangi Gejala Gangguan Stres Pascatrauma Pada Istri Korban Kekerasan Dalam Rumah Tangga
}

\author{
Mada Kartikasari ${ }^{1}$, Fuad Nashori ${ }^{2}$ \\ 1,2 Fakultas Psikologi dan Ilmu Sosial Budaya, Universitas Islam Indonesia, \\ Jl. Kaliurang Km. 14.5, Krawitan, Umbulmartani, Ngemplak, Sleman, Yogyakarta \\ mada.kartikasari01@gmail.com
}

\begin{abstract}
Abstrak
Kekerasan yang dialami oleh istri dapat menyebabkan munculnya gejala gangguan stres pascatrauma. Intervensi untuk mengatasi gangguan stres pascatrauma telah banyak dipublikasi. Namun masih sedikit penelitian yang menggunakan terapi spiritual islami. Penelitian ini bertujuan untuk melihat efektivitas terapi zikir istighfar dalam menurunkan gejala gangguan stres pascatrauma pada istri yang mengalami kekerasan dalam rumah tangga. Partisipan pada penelitian ini adalah 10 orang istri yang menjadi korban kekerasan dalam rumah tangga yang dibagi ke dalam kelompok perlakuan $(n=5)$ dan kelompok kontrol $(n=5)$. Penelitian ini menggunakan metode campuran dengan desain QUAN+qual. Pengumpulan data dilakukan dengan skala The PTSD Checklist for DSM5 (PCL-5) yang memiliki 4 aspek dalam penilaian gangguan stres pascatrauma, observasi dan wawancara. Hasil dari analisis Wilcoxon Sign Rank Test menunjukkan bahwa pada kelompok perlakuan terapi zikir istighfar efektif dalam menurunkan gangguan stress pascatrauma setelah ada waktu untuk menghayati dan mempraktikkan secara mandiri. Hal ini didukung dengan hasil analisis kualitatif yaitu munculnya ketenangan hati dan kesadaran diri akan kesalahan yang dilakukan di masa lalu pada masing-masing partisipan.
\end{abstract}

Kata kunci: kekerasan dalam rumah tangga; gangguan stres pascatrauma; zikir; terapi; istighfar

\begin{abstract}
Violence experienced by women can cause the emergence of symptoms of post-traumatic stress disorder. Interventions to treat post-traumatic stress disorder have been widely published. However, only few studies use Islamic spiritual healing. This study aimed to identify the effectiveness of zikir istighfar therapy to reduce the symptoms of post-traumatic stress disorder in women who had experienced domestic violence. The participants in this study were 10 women who became victims of domestic violence, divided into the treatment group $(n=5)$ and control group $(n=5)$. This research used mixed methods with QUAN+qual design. Data was collected using the PTSD Checklist for DSM-5 (PCL-5) scale with 4 assessment aspects, observation, and interviews. The results of the Wilcoxon Sign Rank Test analysis showed that in the treatment group, zikir istighfar therapy was effective to reduce post-traumatic stress disorder after there was time to live and practice independently. This was supported by the results of qualitative analysis with the emergence of a peace of mind and self-awareness of the past mistakes of each participant.
\end{abstract}

Keywords: domestic violence, istighfar, post-traumatic stress disorder, remembrance, therapy

\section{PENDAHULUAN}

Pernikahan adalah suatu hal yang penting untuk memperoleh keseimbangan hidup. Selain itu, terwujudnya kebahagiaan juga merupakan harapan utama yang diinginkan oleh suami dan istri yang terikat dalam pernikahan. Kebahagiaan pernikahan akan terwujud apabila masingmasing anggota keluarga saling mengerti, menghormati, dan menghargai. Akan tetapi, perjalanan pernikahan belum tentu semudah seperti yang diharapkan. Salah satunya disebabkan adanya kekerasan (Manumpahi et al., 2016). Pada 2019, Komnas Perempuan (2020) menyebutkan, dari jenis kekerasan terhadap perempuan lainnya, kekerasan dalam rumah tangga tercatat memiliki jumlah kasus terbanyak, yaitu $75 \%$ atau sejumlah 11.105 kasus.

Kekerasan dalam rumah tangga merupakan tindakan kekerasan yang bisa dilakukan oleh 
siapapun, seperti ibu, bapak, anak atau bahkan asisten rumah tangga (Manumpahi et al., 2016) (Manumpahi dkk, 2016). Jika dikaji satu persatu mengenai jumlah kasus kekerasan pada masing-masing anggota keluarga tersebut, maka diketahui bahwa kekerasan yang dialami oleh istri menempati peringkat pertama dengan jumlah sebesar 6.555 kasus. Jumlah tersebut meningkat dibandingkan tahun sebelumnya, yaitu sebesar 5.114 kasus (Komnas Perempuan, 2019; Komnas Perempuan, 2020). Data ini menunjukkan bahwa masih banyak istri yang mendapatkan kekerasan dalam ranah rumah tangga.

Adapun beberapa jenis kekerasan yang dapat dialami oleh istri meliputi kekerasan fisik, kekerasan psikis, kekerasan seksual, dan kekerasan ekonomi. Komnas Perempuan (2020) menjabarkan pada tahun 2020 jumlah kasus dari masing-masing jenis kekerasan tersebut, yaitu kekerasan secara fisik sebesar $43 \%$, seksual sebesar $25 \%$, psikis sebesar $19 \%$, dan ekonomi sebesar $13 \%$. Kekerasan yang dialami oleh istri tidak terjadi secara spontan, melainkan memiliki sebab tertentu yang mendorong munculnya kejadian tersebut. Pada dasarnya tidak ada faktor tunggal yang menyebabkan kekerasan pada pasangan (Hayati, 2013). Namun jika dikaji secara ekologi sosial, terdapat beberapa faktor yang mempengaruhi seperti sejarah hidup di masa lalu, kepribadian yang dimiliki oleh suami maupun istri serta beberapa situasi tertentu yang mempengaruhi kehidupan rumah tangga (Heise, 2011). Kekerasan terhadap istri juga dapat disebabkan faktor gender dan patriarki, yaitu laki-laki adalah superior dan perempuan adalah inferior (Muhajarah, 2016).

Namun, jika dikaji secara ideologi agama, sebuah masalah khususnya mengenai kekerasan yang dialami oleh perempuan dalam ranah rumah tangga dapat disebabkan perbuatan atau kesalahan manusia itu sendiri di masa lalu (Muzayanah, 2016). Hal ini diperkuat oleh pendapat Nirwana (2013), bahwa sesungguhnya musibah yang datang dalam kehidupan, disebabkan oleh manusia itu sendiri. Hal ini sebagaimana dijelaskan firman Allah dalam QS. Ali Imran (165): "Dan mengapa ketika kamu ditimpa musibah (pada peperangan Uhud), padahal kamu telah menimpakan kekalahan dua kali lipat kepada musuh-musuhmu (pada peperangan Badar), kamu berkata: "Dari mana datangnya (kekalahan) ini?" Katakanlah: "Itu dari (kesalahan) dirimu sendiri". Sesungguhnya Allah Maha Kuasa atas segala sesuatu."

Kekerasan yang dialami oleh istri tentu akan mempengaruhi kondisi psikis para istri yang menjadi korban kekerasan tersebut. Dampak secara psikis yang dialami juga tentunya akan menyebabkan luka batin yang tersimpan dalam waktu yang lama (Mardiyati, 2015). Adapun dampak psikis secara nyata yang dapat terjadi akibat kekerasan tersebut adalah munculnya perasaan cemas, ketakutan, selalu waspada, murung, sering melamun, mengurung diri bahkan hingga mengalami kesulitan tidur (Maisah \& Yenti, 2016). Istri yang menjadi korban kekerasan dalam rumah tangga ini juga berpotensi mengalami trauma akibat peristiwa kekerasan yang dialaminya. Kondisi trauma tersebut disebabkan oleh sejumlah serangan emosional ekstrem yang didapatkan dari suami, sehingga istri merasa sangat takut dan tertekan terhadap keadaan di rumah (Deborah et al., 2018). Foa dan Rothbaum (dalam Solichah, 2013) menyatakan bahwa bagi sebagian orang, kondisi trauma akan dapat teratasi dengan berjalannya waktu, namun sebagian yang lain tidak. Kondisi trauma yang dapat terjadi selama enam bulan setelah peristiwa traumatis dikenal dengan istilah gangguan stres pascatrauma (Maslim, 2001).

Menurut DeJonghe, Bogat, Levendosky, dan Eye (2008), kekerasan pascatrauma merupakan salah satu gangguan mental yang memiliki keterkaitan dengan kekerasan terhadap pasangan intim (suami dan istri). Penelitian Varma, Chandra, Thomas, dan Carey (2007) menemukan adanya gejala gangguan stres pascatrauma yang lebih tinggi pada perempuan yang melaporkan riwayat kekerasan dari pasangan intim dibandingkan perempuan lain yang tidak mengalaminya. Nathanson, Shorey, Tirone, dan Rhatigan (2012) juga menambahkan bahwa kekerasan yang dialami oleh perempuan dari pasangan intim, dapat menjadi prediktor yang 
signifikan terhadap gangguan stres pascatrauma.

Menurut DSM-5 (American Psychiatric Association, 2013), gangguan stres pascatrauma merupakan suatu gangguan yang memiliki ciri penting atau gejala khas yang muncul setelah terpapar satu atau lebih peristiwa traumatis. Gangguan stres pascatrauma juga dapat diasumsikan sebagai ketidakseimbangan psikologis yang dapat terjadi enam bulan setelah adanya peristiwa traumatis (Mehrad, 2020). Sedangkan menurut Weathers, Marx, Friedman, dan Schnurr (2014), gangguan stres pascatrauma merupakan reaksi yang muncul setelah adanya peristiwa traumatis yang menyebabkan adanya perubahan negatif pada kognisi, emosi, perilaku eksternalisasi dan disosiasi.

Sebagian besar individu yang mengalami gangguan stres pascatrauma akan menyelesaikan masalahnya dengan perilaku yang maladaptif sebagai reaksi dari stres yang dirasakan. Oleh karena itu, perlu dilakukan penanganan yang tepat untuk gangguan stres pascatrauma agar perilaku maladaptif tersebut dapat diubah menjadi adaptif. Berbagai intervensi untuk mengatasi gangguan stres pascatrauma telah banyak dilakukan dan dipublikasikan di berbagai penelitian. Salah satu terapi yang paling sering digunakan adalah cognitive behavior therapy (CBT). Terapi ini bertujuan untuk memodifikasi penilaian negatif, mengoreksi memori yang terkait dengan kejadian traumatis dan menghilangkan perilaku bermasalah pada individu yang mengalami gangguan stres pascatrauma (Watkins et al., 2018).

Rahmania dan Moordiningsih (2012) menjelaskan jenis terapi lainnya yang efektif untuk mengatasi gangguan stres pascatrauma, yaitu dengan menggunakan eye movement desensitization reprocessing (EMDR). Terapi ini dilakukan dengan cara menggabungkan pergerakan mata, pengingatan kembali pada peristiwa traumatis, serta verbalisasi (Connor \& Butterfield, 2003). Beberapa stimulasi ini terus dilakukan hingga tekanan kondisi trauma dalam diri individu tersebut berkurang (Taylor et.al, 2003). Terapi lain yang direkomendasikan untuk penanganan gangguan stres pascatrauma adalah prolonged exposure (PE) (Watkins dkk, 2018). PE merupakan terapi dengan strategi umum untuk mengurangi rasa takut atau cemas yang tidak realistis dengan cara menghadapi pikiran, situasi aktivitas atau orang-orang yang menjadi sumber stresornya (McLean \& Foa, 2011).

Beberapa terapi di atas memiliki fokus pada perbaikan pikiran atau penilaian negatif, strategi dalam menghadapi ketakutan yang kuat terhadap kejadian traumatis serta merubah perilaku maladaptif. Akan tetapi terapi-terapi tersebut tidak menyertakan aspek spiritualitas pada rangkaian proses yang dilakukan. Padahal menurut McBride dan Armstrong (1995), individu yang mengalami trauma sangat membutuhkan pendekatan secara spiritual dan/atau agama. Hal ini dikarenakan individu yang mengalami trauma memiliki perasaan bahwa Tuhan telah mengasingkan dan tidak sayang pada dirinya sehingga individu tersebut mengalami krisis iman dan kekosongan spiritual. Kondisi ini yang pada akhirnya membuat individu tersebut merasa kesulitan untuk memisahkan pikiran maupun perilaku yang benar dan yang salah. Currier, Drescher, dan Harris (2014) juga menjelaskan bahwa faktor-faktor spiritual, secara umum berkorelasi dengan tingkat keparahan gejala gangguan stres pascatrauma.

Dengan demikian, penting untuk mempertimbangkan manfaat dari komponen spiritual dalam menangani gangguan stres pascatrauma (Bormann, Liu, Throp, \& Lang dalam Currier $\mathrm{dkk}, 2014)$. Hal ini dikarenakan beberapa terapi yang bersifat spiritual dianggap mampu mengentaskan gangguan-gangguan psikis pada individu dan menjadi tidak kalah penting dibandingkan dengan psikoterapi psikiatri. Salah satu terapi spiritual yang dapat digunakan sebagai upaya penyembuhan gangguan psikologis serta menyempurnakan kualitas hidup manusia adalah dengan menggunakan terapi spiritual Islami yang berlandaskan pada Al-Qur'an dan As-sunnah (Razak, 2013). Pada dasarnya terapi spiritual Islami dapat dilakukan dengan berbagai macam ibadah yang ditujukan hanya kepada Allah. Namun dari beberapa ibadah 
tersebut, terdapat salah satu ibadah yang efektif untuk dilakukan oleh istri yang memilikin
gangguan stres pascatrauma, yaitu dengan melakukan zikir. Muslaini dan Sofia (2020) menjelaskan bahwa zikir terbukti dapat menurunkan tingkat gangguan stres pascatrauma. (Najati, 2004) juga menjelaskan bahwa salah satu jalan keluar dari munculnya tekanan jiwa yang mengarah pada psikoneurotik adalah melakukan zikrullah, karena menurutnya hal ini dapat membuat jiwa menjadi bersih dan bening serta perasaan yang tenang dan tentram.

Zikir merupakan tradisi ibadah terbaik dan juga paling mudah untuk dilakukan karena tidak memiliki syarat atau aturan tertentu dalam melaksanakannya (Anuar et al., 2017). Selain itu, zikir juga dimaknai sebagai kegiatan spiritual yang efektif untuk membantu proses pengubahan perilaku dan sifat negatif pada seorang Muslim (Mohd Rozali \& Muhammad Nubli, 2013). Saat ini kegiatan zikir telah banyak digunakan dalam berbagai proses terapi dalam bidang psikologi. Hal ini dikarenakan, proses terapi memiliki tujuan untuk penyembuhan dengan cara menghilangkan atau mengubah suatu gejala psikologis tertentu serta meningkatkan pertumbuhan dan perkembangan kepribadian yang positif (Karni, 2014).

Mengacu pada penyebab kekerasan yang dialami istri melalui ideologi agama seperti yang telah disebutkan oleh Muzayanah (2016) dan Nirwana (2019) sebelumnya, maka pernyataan menurut Nashori (2005) mengenai kualitas zikir akan menjadikan jalan keluar dari kondisi tersebut. Zikir yang dilakukan dengan penuh penghayatan akan membawa individu pada kesadaran diri bahwa kejadian yang tidak menyenangkan merupakan ujian dari Allah akibat dari dosa-dosa yang telah diperbuat. Oleh karena itu, dengan kesadaran tersebut, individu akan memiliki dorongan untuk memohon ampunan kepada Allah agar masalah yang dihadapi terasa lebih ringan.

Mulyanti dan Massuhartono (2018) menganjurkan beberapa bacaan zikir yang dapat digunakan dalam proses terapi, yaitu tasbih, tahmid, tauhid, takbir, tahlil, hauqalah, tarji', sholawat dan istighfar. Masing-masing bacaan tersebut tentunya memiliki manfaat yang berbeda-beda. Dari beberapa bacaan tersebut, istighfar merupakan bacaan zikir yang sangat sesuai untuk digunakan untuk interveksi gangguan stres pascatrauma ini. Menurut Shihab (2018), bacaan istighfar dapat digunakan sebagai kesembuhan jiwa dengan adanya pertaubatan sehingga dapat menghapus dosa-dosa tersebut. Penelitian ini bertujuan untuk mengetahui efektivitas terapi zikir istighfar dalam mengurangi gejala gangguan stres pascatrauma pada istri yang menjadi korban kekerasan dalam rumah tangga. Berdasarkan hal tersebut, peneliti mengajukan hipotesis bahwa ada pengaruh terapi zikir istighfar terhadap penurunan gejala gangguan stres pascatrauma. Hal ini dapat dilihat dari adanya perbedaan skor pada gejala gangguan stres pascatrauma di dalam kelompok perlakuan dan kelompok kontrol antara sebelum dan sesudah maupun setelah dua minggu diberikan terapi zikir istighfar.

\section{METODE}

Partisipan pada penelitian ini adalah istri yang menjadi korban kekerasan dalam rumah tangga yang didapatkan dari beberapa lembaga atau instansi penanganan kasus kekerasan dalam rumah tangga. Pemilihan partisipan dilakukan secara purposive sampling dengan menyesuaikan karakteristik partisipan yang dibutuhkan. Adapun karakteristik tersebut, yaitu terindikasi gejala gangguan stres pascatrauma pada alat ukur The PTSD Checklist for DSM-5 (PCL-5) dengan skor 31-33, berusia antara 24-50 tahun dan beragama Islam. Jumlah partisipan pada penelitian ini sebanyak 10 orang yang dibagi ke dalam dua kelompok, yaitu lima orang dalam kelompok perlakuan dan lima orang dalam kelompok kontrol.

Penelitian ini menggunakan metode campuran, yaitu dengan menggabungkan unsur dari pendekatan kuantitatif dan kualitatif. Desain yang digunakan pada metode ini adalah $Q U A N+q u a l$, yaitu mengutamakan hasil dari pendekatan kuantitatif dan menjadikan 
pendekatan kualitatif sebagai komponen pelengkapnya (Morse \& Linda, dalam Schoonenboom \& Johnson, 2017). Pada pendekatan kuantitatif, peneliti menggunakan desain quasi experimental nonrandomized pretest-posttest control group design. Desain penelitian ini menggunakan dua kelompok, yaitu kelompok perlakuan yang diberikan intervensi dan kelompok kontrol yang tidak mendapatkan perlakuan sama sekali. Kemudian kedua kelompok tersebut diberikan pengukuran yaitu prates dan pascates untuk mengetahui perbedaan kondisi antara kelompok yang diberikan perlakuan dan yang tidak (Levy \& Ellis, 2011). Sedangkan pada pendekatan kualitatif, peneliti menggunakan teknik observasi dan wawancara dengan setting alamiah dan sumber data primer, yaitu menjadikan partisipan secara langsung sebagai sumber data utama (Sugiyono, 2010).

Tabel 1.

Rancangan Eksperimen Penelitian

\begin{tabular}{ccccc}
\hline Kelompok & Prates & Intervensi & Pascates & Tindak lanjut \\
\hline KP & $\mathrm{O} 1$ & $\mathrm{X}$ & $\mathrm{O} 2$ & $\mathrm{O} 3$ \\
\hline KK & $\mathrm{O} 1$ & - & $\mathrm{O} 2$ & $\mathrm{O} 3$ \\
\hline
\end{tabular}

Keterangan:

KP : Kelompok Perlakuan

KK : Kelompok Kontrol

O1 : Hasil pengukuran prates

$\mathrm{O} 2$ : Hasil pengukuran pascates

$\mathrm{X}$ : Intervensi

O3 : Hasil pengukuran tindak lanjut

Selanjutnya untuk pengelompokan pada sampel yang telah terpilih dilakukan dengan random assignment to groups dengan menggunakan pengacakan terkomputerisasi. Teknik ini dilakukan sebagai sebuah usaha untuk mengendalikan variabel luar atau extraneous variable.

Pengumpulan data dilakukan dengan menggunakan beberapa teknik, yaitu skala, observasi dan wawancara. Skala yang digunakan adalah The PTSD Checklist for DSM-5 (PCL-5) yang dikembangkan oleh F. W. Weathers et al., (2013). Skala ini memiliki tujuan untuk melihat ada dan beratnya gejala gangguan stres pacatrauma pada individu yang telah terpapar peristiwa traumatis. Total soal pada PCL-5 ini sebanyak 20 item yang terbagi dalam 4 aspek. Adapun aspek-aspek tersebut, yaitu kilas balik atau intrusi yang diwakili oleh 5 item, penghindaran yang diwakili oleh 2 item, perubahan negatif dalam kognisi dan suasana hati yang diwakili oleh 7 item serta gairah dan reaktivitas yang diwakili oleh 6 item. Seseorang dapat diindikasi mengalami gejala gangguan stres pascatrauma jika minimal skor yang didapatkan sebesar 3133.

PCL-5 ini telah diadaptasi ke bahasa Indonesia dengan menggunakan metode translasi forward-backward sesuai dengan pedoman dari International Test Commission (ITC) Guidelines for Translating and Adapting Tests (2017). Hasil dari adaptasi tersebut ini didapatkan koefisien validitas item yang bergerak dari angka 0,301-0,748 ( $r>0,30)$ dan koefisien alpha cronbach sebesar 0,919.

Intervensi dilakukan dengan menggunakan panduan modul yang disusun oleh tim peneliti dengan melakukan modifikasi dari modul Wulandari dan Nashori (2014) serta Kumala, Rusdi, dan Rumiani (2019) yang telah disesuaikan dengan tahapan terapi zikir menurut Subandi (2019). Beberapa hal yang dimodifikasi dari kedua modul tersebut adalah penyesuaian konteks penggunaan modul, penggunaan bacaan zikir serta penambahan materi mengenai pemahaman dari gejala gangguan psikologis yang dimiliki oleh partisipan. Pelaksanaan terapi zikir istighfar pada modul ini terdiri atas 12 sesi yang terbagi dalam tiga kali pertemuan dengan durasi waktu 
sekitar 120 menit setiap pertemuan.

Tahapan pada pertemuan pertama adalah pemberian psikoedukasi kepada partisipan mengenai zikir, terutama zikir istighfar. Lalu pada tahap pertemuan kedua, partisipan diajarkan mengenai cara dalam berzikir yang benar dan mempraktekkannya. Adapun urutan cara berzikir yang benar adalah diawali dengan berwudhu, lalu berniat memohon pertolongan dan petunjuk kepada Allah SWT, membaca ta'awudz, bershalawat, membaca Al-Fatihah dan kemudian membaca istighfar. Pada pertemuan ketiga, yaitu adanya tahapan refleksi dan evaluasi dari praktik zikir istighfar yang telah dilakukan oleh partisipan selama proses terapi. Setiap akhir sesi, partisipan diminta untuk melakukan tugas rumah dengan membiasakan diri untuk berzikir istighfar dan menuliskan perasaan serta pengalamannya setelah melakukan hal tersebut.

Pengujian hipotesis pada analisis kuantitatif dilakukan dengan menggunakan analisis statistik Wilcoxon Sign Rank Test. Wilcoxon Sign Rank Test merupakan uji analisis nonparametrik yang digunakan untuk membandingkan dua sampel terkait atau pengukuran berulang pada sampel tunggal tanpa memerlukan normalitas (Oyeka \& Ebuh, 2012; Imam, Mohammed, \& Moses Abanyam, 2014). Sedangkan analisis data kualitatif dilakukan dengan analisis deskriptif dengan mengolah data yang diperoleh dari observasi dan wawancara selama proses terapi berlangsung sampai dengan tindak lanjut kepada partisipan eksperimen.

\section{HASIL}

Partisipan pada penelitian ini terdiri atas sepuluh orang wanita yang mengalami kekerasan dari suami. Partisipan tersebut dibagi kedalam dua kelompok, yaitu lima orang pada kelompok perlakuan dan lima orang lainnya pada kelompok kontrol. Rincian deskripsi data pada masingmasing partisipan tersebut tercantum pada Tabel 2.

Tabel 2.

Deskripsi Partisipan Penelitian $(\mathrm{N}=10)$

\begin{tabular}{cccccc}
\hline Kelompok & Nama & Usia & Status Pernikahan & $\begin{array}{c}\text { Jenis } \\
\text { KDRT }\end{array}$ & $\begin{array}{c}\text { Skor } \\
\text { PCL-5 }\end{array}$ \\
\hline \multirow{6}{*}{ Perlakuan } & MY & 46 & Menikah & Psikologis & 48 \\
& AM & 24 & Proses Cerai & Psikologis & 36 \\
& AT & 52 & Menikah & Psikologis & 35 \\
& LL & 37 & Menikah & Psikologis & 47 \\
& WL & 39 & Cerai Hidup & Psikologis & 69 \\
\hline \multirow{6}{*}{ Kontrol } & NN & 23 & Cerai Hidup & Psikologis & 55 \\
& FR & 34 & Proses Cerai & Psikologis & 37 \\
& RS & 41 & Menikah & Psikologis & 50 \\
& ID & 42 & Menikah & Psikologis & 33 \\
& ZA & 30 & Menikah & Fisik & 31 \\
\hline
\end{tabular}

Seluruh partisipan diukur dengan menggunakan PCL-5 yang dilakukan sebanyak tiga kali, yaitu sebelum diberikan terapi, setelah diberikan terapi dan ditindaklanjuti setelah dua minggu dari berakhirnya rangkaian terapi. Adapun perubahan skor PCL-5 pada kelompok perlakuan maupun kelompok kontrol dalam setiap pengukuran adalah sebagai berikut: 
Tabel 3.

Deskripsi Analisis Data Skor PCL-5 Kelompok Perlakuan

\begin{tabular}{ccccccc}
\hline Nama & Prates & Pascates & $\begin{array}{c}\text { Tindak } \\
\text { Lanjut }\end{array}$ & $\begin{array}{c}\text { Gained } \\
\text { Score } \\
\text { (Pra-Pasca) }\end{array}$ & $\begin{array}{c}\text { Gained-Score } \\
\text { (Pasca-Tindak } \\
\text { Lanjut) }\end{array}$ & $\begin{array}{c}\text { Gained Score } \\
\text { (Pra-Tindak } \\
\text { Lanjut) }\end{array}$ \\
\hline MY & 48 & 48 & 29 & 0 & -19 & -19 \\
AM & 36 & 26 & 11 & -10 & -15 & -25 \\
AT & 35 & 34 & 34 & -1 & 0 & -1 \\
LL & 47 & 18 & 24 & -29 & 6 & -23 \\
WL & 69 & 59 & 66 & -10 & 7 & -3 \\
\hline
\end{tabular}

Tabel 3 menunjukkan bahwa adanya perubahan skor pada kelompok perlakuan sebelum dan sesudah bahkan hingga pengukuran tindak lanjut setelah diberikan terapi zikir istighfar. Hal ini dapat dilihat dari pengukuran prates hingga pascates, yaitu terdapat beberapa partisipan yang mengalami penurunan skor dari -29 hingga - 1. Namun juga terdapat partisipan lainnya yang tidak mengalami perubahan skor. Selanjutnya, jika dilihat dari hasil pengukuran pascates ke tindak lanjut, terdapat dua partisipan yang mengalami penurunan skor secara signifikan, yaitu dari -19 hingga -15. Akan tetapi, satu partisipan lainnya tidak mengalami perubahan skor dan dua partisipan selanjutnya justru mengalami peningkatan yaitu dari skor 6 hingga 7. Jika dilihat secara keseluruhan, semua partisipan mengalami penurunan skor dari pengukuran prates ke tindak lanjut.

Tabel 4.

Deskripsi Analisis Data Skor PCL-5 Kelompok Kontrol

\begin{tabular}{ccccccc}
\hline Nama & Prates & Pascates & $\begin{array}{c}\text { Tindak } \\
\text { Lanjut }\end{array}$ & $\begin{array}{c}\text { Gained } \\
\text { Score } \\
\text { (Pra-Pasca) }\end{array}$ & $\begin{array}{c}\text { Gained Score } \\
\text { (Pasca-Tindak } \\
\text { Lanjut) }\end{array}$ & $\begin{array}{c}\text { Gained Score } \\
\text { (Pra-Tindak } \\
\text { Lanjut) }\end{array}$ \\
\hline NN & 55 & 67 & 58 & 12 & -9 & 3 \\
FR & 37 & 52 & 47 & 15 & -5 & 10 \\
RS & 50 & 50 & 56 & 0 & 6 & 6 \\
ID & 33 & 35 & 20 & 2 & -15 & -13 \\
ZA & 31 & 30 & 28 & -1 & -2 & -3 \\
\hline
\end{tabular}

Tabel 4, memperlihatkan adanya perubahan skor yang dialami oleh partisipan didalam kelompok kontrol. Pada pengukuran prates ke pascates menunjukkan adanya beberapa partisipan yang mengalami peningkatan skor, yaitu dari 2 sampai 15. Sedangkan satu partisipan lainnya memiliki skor yang sama dengan sebelumnya dan satu partisipan lagi mengalami penurunan skor sebesar 1 poin. Kemudian pada pengukuran pascates ke tindak lanjut, hampir semua partisipan mengalami penurunan, yaitu dari skor -2 hingga -15 . Namun, terdapat satu partisipan yang mengalami peningkatan skor sebesar 6 poin. Jika dilihat secara keseluruhan dari pengukuran prates hingga tindak lanjut, terdapat tiga partisipan yang mengalami peningkatan skor, yaitu dari skor 3 hingga 6 . Sedangkan dua partisipan lainnya mengalami penurunan skor, yaitu dari -3 sampai -13 . 
Tabel 5.

Deskripsi Data Statistik

\begin{tabular}{ccccccccc}
\hline & \multicolumn{4}{c}{ Kelompok Perlakuan } & \multicolumn{3}{c}{ Kelompok Kontrol } \\
\cline { 2 - 8 } & Min & Max & Mean & SD & Min & Max & Mean & SD \\
\hline Prates & 35 & 69 & 47.00 & 13.69 & 31 & 55 & 41.20 & 10.67 \\
Pascates & 18 & 59 & 37.00 & 16.55 & 30 & 67 & 46.80 & 14.72 \\
Tindak & 11 & 66 & 32.80 & 20.44 & 20 & 58 & 41.80 & 17.00 \\
Lanjut & & & & & & & &
\end{tabular}

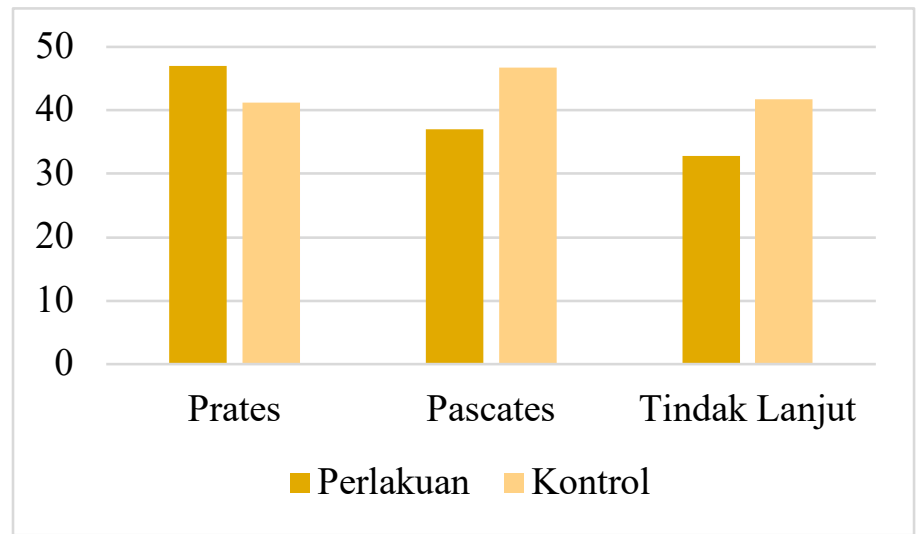

Gambar 1. Perbedaan Rerata Skor PCL-5 Kelompok Perlakuan dan Kontrol

Berdasarkan perolehan data skor PCL-5 pada setiap pengukuran terhadap istri yang mengalami kekerasan di kelompok perlakuan, diketahui bahwa ada penurunan nilai rata-rata setelah diberikan terapi zikir istighfar. Adapun perubahan tersebut dapat dilihat dari pengukuran prates (Mean=47.00; $S D=13.69)$ ke pascates (Mean=37.00; $S D=16.55)$ hingga tindak lanjut (Mean=32.80; $S D=20.44)$. Sedangkan nilai rata-rata pada kelompok kontrol mengalami peningkatan dari pengukuran prates (Mean $=41.20 ; S D=10.67$ ) hingga pascates (Mean=46.80; $S D=14.72$ ). Walaupun setelahnya nilai tersebut mengalami penurunan pada pengukuran tindak lanjut (Mean $=41.80 ; S D=17.00$ ), namun pada dasarnya nilai rata-rata pada kelompok kontrol mengalami sedikit peningkatan jika dilihat dari pengukuran prates hingga tindak lanjut. Hal ini diperkuat oleh Gambar 1 yang menunjukkan bahwa adanya penurunan skor yang signifikan pada kelompok perlakuan dibandingkan kelompok kontrol.

Tabel 6.

Hasil Uji Hipotesis

\begin{tabular}{ccccc}
\hline Pengukuran & \multicolumn{2}{c}{ Kelompok Perlakuan } & \multicolumn{2}{c}{ Kelompok Kontrol } \\
\cline { 2 - 5 } & $\mathbf{Z}$ & $\mathbf{p}$ & $\mathbf{Z}$ & $\mathbf{p}$ \\
\hline Prates-Pascates & -1.841 & 0.066 & -1.461 & 0.144 \\
Pascates - Tindak Lanjut & -0.730 & 0.465 & -1.241 & 0.225 \\
Prates-Tindak Lanjut & -2.023 & 0.043 & -0.271 & 0.786 \\
\hline
\end{tabular}

Pada Pada penelitian ini, uji hipotesis dilakukan dengan menggunakan metode analisis Wilcoxon Sign Rank Test yang tercantum pada Tabel 6. Hasil pengukuran prates ke pascates $(Z=-1.841$ dan $p=0.066 ; p>0.05)$ dan pascates ke tindak lanjut $(Z=-0.730$ dan $p=0.465 ; p>0.05)$ di dalam kelompok perlakuan menunjukkan tidak ada perbedaan pada tingkat gejala gangguan stres pascatrauma di antara waktu pengukuran tersebut. Namun jika dilihat pada pengukuran 
prates ke tindak lanjut $(Z=-2.023$ dan $p=0.043 ; p>0.05)$ terlihat bahwa adanya perbedaan yang
signifikan pada gejala gangguan stres pascatrauma di antara waktu pengukuran tersebut. Hasil penelitian menunjukkan bahwa pada kelompok perlakuan terapi zikir istighfar efektif dalam menurunkan gangguan stress pascatrauma pada istri korban kekerasan dalam rumah tangga setelah ada waktu untuk menghayati dan mempraktikkan secara mandiri.

Sedangkan hasil uji beda pada kelompok kontrol menunjukkan tidak adanya perbedaan yang signifikan secara keseluruhan di antara masing-masing waktu pengukuran. Hal ini ditunjukkan dari hasil pengukuran prates ke pascates $(Z=-1.241$ dan $p=0.225 ; p>0.05)$, pascates ke tindak lanjut $(Z=-2.023$ dan $p=0.043 ; p>0.05)$, maupun prates ke tindak lanjut $(Z=-0.271$ dan $\mathrm{p}=0.786 ; \mathrm{p}>0.05)$. Berdasarkan uraian di atas, menunjukkan bahwa perbedaan tingkat gejala gangguan stres pascatrauma hanya terjadi di dalam kelompok perlakuan sebelum diberikan terapi zikir istighfar serta saat pengukuran tindak lanjut.

Penelitian ini juga didukung dengan hasil analisis kualitatif yang dilakukan melalui wawancara dan observasi terhadap partisipan di dalam kelompok perlakuan. Adapun beberapa pertanyaan yang menjadi pedoman dalam wawancara adalah konsistensi pelaksanaan zikir istighfar dalam keseharian; perasaan, perbedaan serta manfaat yang dirasakan setelah mengikuti terapi; perubahan aspek-aspek gangguan stres pascatrauma yang dimiliki serta pelaksanaan langkah perbaikan yang telah disusun. Sedangkan beberapa hal yang diobservasi pada partisipan yaitu terdiri dari kesan umum yang meliputi kondisi fisik dan penampilan; hubungan partisipan dengan orang disekitarnya; sikap atau respon dan keaktifan partisipan selama mengikuti terapi.

Hasil yang didapatkan dari analisis kualitatif menyebutkan bahwa MY merasa adanya perubahan dalam dirinya setelah melakukan aktivitas zikir istighfar dan ditambah dengan informasi yang didapatkan dari sosial media mengenai cara berpikir positif. Perubahan yang dirasakan yaitu, MY merasa lebih mampu untuk mengendalikan diri maupun perasaan sedih yang muncul dibanding sebelumnya. MY juga merasa lebih tenang, sehingga MY tidak memikirkan permasalahan yang dialami hingga berlarut-larut. Selain itu, MY juga merasa semakin ikhlas dan menerima takdir yang diberikan oleh Allah terhadap kehidupan rumah tangga. MY mampu mendapatkan manfaat dari proses tersebut walaupun MY selalu terlambat datang saat terapi dilaksanakan.

AM juga merasa lebih tenang dan bersyukur setelah rutin beristighfar, meskipun AM tampak tidak begitu aktif dan lebih banyak diam saat proses terapi dilaksanakan. Selain itu, AM juga merasa bahwa banyak kemudahan yang diterima setelah AM sering membaca zikir istighfar dalam kesehariannya. Bahkan AM juga tidak lagi menyalahkan dirinya, karena bagi AM, permasalahan yang sedang AM alami merupakan takdir dari Allah, sehingga AM yakin bahwa Allah akan membantu AM untuk menyelesaikannya. Sedangkan AT menjadi yakin bahwa Allah akan memberikan kemudahan. AT juga meyakini bahwa permasalahan yang menimpa rumah tangga AT merupakan teguran dari Allah atas kesalahan yang secara sengaja atau tidak sengaja AT lakukan di masa lalu. AT seringkali menangis saat proses terapi dilaksanakan, terutama saat membaca istighfar bersama.

Kemudian partisipan lain, yaitu LL dapat menyadari bahwa permasalahan yang terjadi di rumah tangganya juga terdapat kontribusi kesalahan yang telah dilakukan oleh dirinya. Walaupun LL juga mengaku bahwa mimpi buruk terkait perselingkuhan suaminya masih sering muncul, namun LL tidak terbebani lagi pada mimpi buruk tersebut. Kondisi tersebut terjadi karena LL selalu membaca zikir istighfar dalam setiap aktivitasnya. Walaupun, selama proses terapi, LL tampak lebih banyak diam. Selain itu, WL juga berhasil untuk tidak mengkonsumsi obat tidur kembali karena WL selalu membaca zikir istighfar sebelum tidur. WL merasa zikir istighfar yang dilakukannya tersebut mampu membuat WL lebih tenang dan lebih mudah untuk 
tertidur. Bahkan ketika WL mulai menyalahkan dirinya kembali, WL mampu untuk mengendalikan pikiran tersebut agar tidak berlarut-larut. WL juga merupakan peserta paling aktif dan seringkali memberikan dukungan kepada sesama peserta lainnya. Selain itu, seluruh peserta juga berkomitmen untuk terus melaksanakan zikir istighfar secara konsisten dalam kesehariannya.

\section{DISKUSI}

Penelitian ini dilakukan untuk mengetahui efektivitas terapi zikir istighfar dalam mengurangi gejala gangguan stres pascatrauma pada istri yang mengalami kekerasan dalam rumah tangga. Berdasarkan analisis kuantitatif yang dilakukan, diketahui nilai signifikansi pada uji hipotesis menunjukkan adanya perbedaan yang signifikan antara waktu pengukuran prates dan tindak lanjut pada kelompok perlakuan. Dengan demikian, dapat dikatakan bahwa hipotesis dari penelitian ini diterima. Artinya, terapi zikir istighfar memiliki pengaruh terhadap pengurangan gejala gangguan stres pascatrauma pada istri yang mengalami kekerasan, walaupun pengaruh tersebut baru dirasakan setelah dua minggu dari berakhirnya rangkaian terapi. Dengan demikian, dapat dikatakan bahwa para istri yang mengalami kekerasan membutuhkan waktu untuk menghayati aktivitas zikir istighfar yang dilakukan.

Hasil penelitian ini mendukung pandangan Muslaini dan Sofia (2020) bahwa aktivitas spiritual yang dilakukan dengan berzikir secara terus menerus dan penuh kekhusyukan, dapat menentramkan dan menimbulkan efek relaksasi bagi individu yang sedang dalam masa penyembuhan trauma. (Pajević et al., 2017) juga menjelaskan bahwa penggunaan aktivitas keislaman yang dilakukan secara rutin dapat memudahkan proses penyembuhan kesehatan jiwa, seperti gangguan stres pascatrauma ataupun psikotrauma lainnya. Zikir dengan bacaan istighfar dapat digunakan sebagai kesembuhan jiwa. Hal ini dikarenakan istighfar dapat dimaknai sebagai permohonan ampun agar Allah menutupi dosa ataupun aib seseorang. Selain itu, bacaan istighfar juga dapat bermakna sebagai penyesalan atas dosa-dosa. Sehingga kesembuhan jiwa akan dirasakan ketika Allah telah menghapus dosa-dosa tersebut (Shihab, 2018). Hasil dari penelitian ini juga mendukung penelitian Uyun, Jaufalaily, Witruk, dan Kurniawan (2020) yang menyatakan bahwa terapi taubat dan istighfar yang dilakukan secara serius pada setiap tahapan dapat efektif untuk menurunkan gangguan stres pascatrauma.

Peristiwa kekerasan yang dialami oleh seorang istri tidak hanya memberikan dampak luar biasa pada kondisi psikologis, namun juga pada dimensi spiritualitas yang membuat seseorang kehilangan makna hidup (Wilson \& Moran, 1998). Hal ini dikarenakan individu tersebut mempertanyakan keberadaan dan keadilan Tuhan bahkan hingga menyalahkan Tuhan, sehingga membuat individu tersebut sulit untuk memandang kehidupan secara positif (Slater et al., 2016). Upaya perawatan psikologis pada korban yang memiliki gangguan stres pascatrauma dapat dilakukan dengan meningkatkan iman dan spiritual (Wilson \& Moran, 1998). Meichenbaum dan Emeritus (2008) menambahkan bahwa aktivitas koping spiritual dapat meningkatkan kesejahteraan emosional bagi individu yang mengalami gangguan stres pascatrauma. Aktivitas spiritual dan keagamaan dapat menjadi sumber dukungan emosional dan sebagai cara untuk meningkatkan kondisi diri menjadi lebih positif (Niewiadomska et al., 2021).

Hasil kuantitatif tersebut diperkuat oleh hasil analisis kualitatif yang dilakukan, bahwa pada dasarnya seluruh partisipan merasakan perbedaan kondisi diri dan manfaat setelah mengikuti terapi zikir istighfar. Salah satu manfaat yang paling dirasakan adalah ketenangan hati. Menurut Burhanuddin (2020), zikir merupakan salah satu solusi yang diberikan oleh agama Islam agar manusia senantiasa merasakan ketenangan dan kedamaian hati ketika sedang menghadapi persoalan yang dihadapi. Zikir juga membawa pengaruh yang sangat positif dalam 
kehidupan manusia, yaitu untuk menuju kesempurnaan hidup dan ketenangan jiwa manusia itu sendiri (Ilyas, 2017). Salah satu zikir yang dapat digunakan adalah istighfar, karena dengan beristighfar seseorang akan memohon ampunan atas kesalahan yang dilakukan dan hal ini merupakan proses penyembuhan jiwa agar tercipta ketenangan hati (Uyun et al., 2020). Istighfar juga dapat digunakan sebagai proses membersihkan diri sehingga hal tersebut dapat membawa kedamaian batin dan menghasilkan solusi dari keadaan sulit yang dialami. Allah mendorong setiap manusia untuk beristighfar agar manusia dapat menemukan kebahagiaan dan ketenangan dalam kehidupannya (Karakaş \& Geçimli, 2017).

Selain ketenangan hati, beberapa partisipan juga menyadari bahwa permasalahan yang dihadapinya saat ini merupakan dampak dari kesalahan atau dosa yang pernah dilakukan di masa lalu. Konflik yang terjadi di dalam suatu hubungan juga dapat dikategorikan sebagai perbuatan dosa. Perbuatan dosa tersebut dapat memicu tekanan psikologis yang mempengaruhi buruknya kesejahteraan mental seseorang. Permohonan ampun dan bertaubat kepada Allah dapat membantu seseorang dalam menyucikan jiwa sehingga penyakit jiwa yang dimiliki dapat teratasi (Uyun et al., 2019). Permohonan ampun tersebut dapat dilakukan dengan membaca istighfar, karena dengan beristighfar seseorang akan selalu mengingat Allah dan percaya bahwa Allah juga yang memberikan ujian dalam kehidupannya (Uyun et al, 2020). Dengan kesadaran tersebut individu harus berusaha untuk menyelesaikan masalahnya dengan menyertakan Allah. Hal ini dikarenakan apabila seseorang meyakini bahwa ujian yang datang berasal dari Allah, maka ia akan lebih mudah untuk berlapang dada (Nashori, 2005).

Beberapa peserta juga menyatakan bahwa gejala dari gangguan stres pascatrauma yang dimilikinya semakin berkurang atau jika gejala tersebut masih muncul, para partisipan dapat mengontrol kondisi dirinya agar tetap stabil. Magezi dan Manda (2016) menjelaskan bahwa dengan pendekatan spiritualitas dan campur tangan Tuhan dapat membantu seseorang mengatasi situasi trauma yang dialaminya. Upaya mengatasi dan/atau sebagai upaya pencegahan timbulnya gejala dari gangguan stres pascatrauma dapat dilakukan dengan berzikir (Muslaini \& Sofia, 2020). Hal ini dikarenakan zikir merupakan teknik meditasi dalam Islam, yaitu dengan melakukan perenungan terhadap dosa yang dimiliki dan sebagai cara untuk mendekatkan diri serta memohon ampunan kepada Allah. Aktivitas tersebut memberikan efek yang baik untuk mengurangi gejala dari gangguan stres pascatrauma (Sasmita et al., 2021).

Salah satu pengurangan gejala gangguan stres pascatrauma yang dirasakan oleh peserta, yaitu pola tidur yang lebih teratur. Hal ini dikarenakan terapi dengan memberikan bacaan zikir merupakan salah satu terapi non-farmakologis yang memiliki potensi untuk memperbaiki kualitas tidur seseorang(Reflio et al., 2016). Kondisi ini disebabkan aktivitas zikir yang dilakukan secara berulang dapat menimbulkan pengaruh secara fisiologis, yaitu menurunnya kecepatan detak jantung, kecepatan nafas, tekanan darah dan kecepatan metabolisme. Kondisi ini membawa efek tenang yang membantu seseorang untuk dapat tertidur (Riyadi, 2020). Bahkan terdapat salah satu peserta yang berhasil untuk tidak mengkonsumsi obat tidur kembali. Kondisi ini terjadi karena adanya kegiatan spiritual yang salah satunya adalah berzikir. Hal ini dikarenakan dengan berzikir dapat meningkatkan spiritual yang mempengaruhi cara seseorang dalam mengendalikan diri dan emosi serta menjadi lebih tenang (Komarudin \& Halim, 2021).

Penelitian ini memiliki beberapa keterbatasan, yaitu terkait dengan kontrol terhadap validitas internal. Menurut Hastjarjo (2016), terdapat sejumlah ancaman validitas yang dapat mempengaruhi kesimpulan dari suatu penelitian. Salah satu ancaman yang paling mendekati dengan kondisi penelitian ini adalah ancaman pada validitas internal yang disebabkan oleh sejarah atau adanya suatu kejadian yang berlangsung secara bersamaan dengan perlakuan yang diberikan. Flannelly, Flannelly, dan Jankowski (2018) menambahkan bahwa ancaman pada validitas internal ini tidak akan terjadi apabila penelitian dilakukan dalam durasi waktu yang 
singkat. Namun, jika penelitian dilakukan selama berhari-hari atau berminggu-minggu maka pengalaman yang dialami dalam keseharian partisipan dapat menjadi variabel luar atau extraneous variable.

Ancaman validitas internal yang disebabkan oleh sejarah tersebut dipengaruhi oleh ancaman validitas internal lainnya yaitu terkait dengan seleksi partisipan yang efeknya dapat teramati pada hasil penelitian (Hastjarjo, 2016). Kondisi ini disebabkan adanya ketidaksetaraan atau perbedaan secara sistematik pada status pernikahan dari masing-masing partisipan. Perbedaan status pernikahan tersebut menimbulkan adanya perbedaan stressor yang dialami dari masing-masing partisipan. Selain itu, ancaman validitas internal yang disebabkan oleh sejarah juga terjadi karena adanya materi atau informasi lain yang diterima oleh partisipan dari sosial media selama rangkaian proses terapi dilaksanakan. Sehingga informasi tersebut juga dapat menjadi variabel luar atau extraneous variable.

Keterbatasan selanjutnya yaitu terkait dengan ketepatan waktu dari kehadiran partisipan selama terapi dilaksanakan. Ketepatan waktu hadir tersebut dapat mempengaruhi pemahaman secara utuh pada materi yang diberikan. Kemudian kurang dijelaskannya secara rinci dan mendalam mengenai materi gejala gangguan stres pascatrauma dan hubungan antara gejala tersebut dengan terapi zikir istighfar membuat partisipan kurang optimal dalam memahaminya secara keseluruhan. Selain itu, penggunaan aplikasi zikir yang bertujuan untuk mengontrol aktivitas zikir pada masing-masing partisipan juga menjadi tidak optimal. Hal ini dikarenakan aplikasi tersebut hanya dapat digunakan melalui Handphone dan proses zikir yang dilakukan oleh partisipan tidak selalu dalam kondisi yang memungkinkan untuk menggunakan Handphone, seperti saat di jalan atau saat sedang memasak dan mengasuh anak.

\section{KESIMPULAN}

Terapi zikir istighfar memiliki pengaruh pada penurunan gejala gangguan stres pascatrauma bagi istri yang menjadi korban kekerasan dalam rumah tangga. Hasil menunjukkan adanya perubahan pada kondisi yang dirasakan pada masing-masing peserta setelah melaksanakan terapi zikir istighfar, terutama setelah pemberian psikoedukasi dan saat praktik membaca istighfar secara bersama-sama maupun secara mandiri dalam penugasan. Melalui terapi zikir partisipan mendapatkan manfaat ketenangan hati, menyadari atas kesalahan yang pernah dibuat di masa lalu, meyakini bahwa permasalahan yang dialami merupakan takdir dari Allah dan berkurangnya gejala pada gangguan stres pascatrauma serta memiliki coping yang baik dalam mengatasi gejala yang muncul.

Melalui penelitian ini Partisipan diharapkan mampu berkomitmen untuk melaksanakan terapi zikir istighfar secara konsisten di dalam kesehariannya. Hal ini bertujuan agar partisipan semakin merasakan manfaat dan mampu untuk meningkatkan kemampuan coping yang baik dalam mengatasi gejala gangguan stres pascatrauma yang muncul. Kemudian penelitian selanjutnya diharapkan mampu untuk mengontrol secara optimal validitas internal. Hal ini dapat diupayakan agar perlakuan yang diberikan menjadi lebih efektif. Penelitian selanjutnya juga diharapkan dapat membuat system pencatatan zikir yang lebih efisien agar memudahkan partisipan dalam mencatat zikir yang dilakukan dalam kesehariannya.

\section{DAFTAR PUSTAKA}

Aida Mehrad. (2020). Post-Traumatic Stress Disorder (PTSD) Effect of Coronavirus (COVID19) Pandemic and Role of Emotional Intelligence. Journal of Social Science Research, 15(May), 185-190. https://doi.org/10.24297/jssr.v15i.8750 
Anaene Oyeka, I. C., \& Ebuh, G. U. (2012). Modified Wilcoxon Signed-Rank Test. Open Journal of Statistics, 02(02), 172-176. https://doi.org/10.4236/ojs.2012.22019

Anuar, A. I. M., Nubli, A. W. M., \& Yusma, M. Y. N. (2017). The Significant Effect of Wudu' and Zikr in the Controlling of Emotional Pressure Using Biofeedback Emwave Technique. International Journal of Social, Behavioral, Educational, Economic, Business and Industrial Engineering, 1(4), 828-834.

Burhanuddin, B. (2020). Zikir Dan Ketenangan Jiwa (Solusi Islam Mengatasi Kegelisahan dan Kegalauan Jiwa). Jurnal Mimbar: Media Intelektual Muslim Dan Bimbingan Rohani, 6(1), 1-25. https://doi.org/10.47435/mimbar.v6i1.371

Connor, K. M., \& Butterfield, M. I. (2003). Posttraumatic Stress Disorder. I(3).

Currier, J. M., Drescher, K. D., \& Irene Harris, J. (2014). Spiritual functioning among veterans seeking residential treatment for PTSD: A Matched Control Group Study. Spirituality in Clinical Practice, 1(1), 3-15. https://doi.org/10.1037/scp0000004

Deborah, S., Muthmainnah, A., Herlinda, L., \& Tanawi, S. S. (2018). Trauma dan Resiliensi pada Wanita Penyintas Kekerasan dalam Rumah Tangga. Jurnal Ilmiah Psikologi MANASA, 7(2), 121-130.

DeJonghe, E., Bogat, G., Levendosky, A., \& Eye, A. (2008). Women survivors of intimate partner violence and post-traumatic stress disorder: Prediction and prevention. Journal of Postgraduate Medicine, 54(4), 294-300. https://doi.org/10.4103/0022-3859.41435

Dwi Kumala, O., Rusdi, A., \& Rumiani, R. (2019). Terapi Dzikir Untuk Meningkatkan Ketenangan Hati Pada Pengguna Napza. Jurnal Intervensi Psikologi (JIP), 11(1), 43-54. https://doi.org/10.20885/intervensipsikologi.vol11.iss1.art4

Flannelly, K. J., Flannelly, L. T., \& Jankowski, K. R. B. (2018). Threats to the internal validity of experimental and quasi-experimental research in healthcare. Journal of Health Care Chaplaincy, 24(3), 107-130. https://doi.org/10.1080/08854726.2017.1421019

Hastjarjo, T. D. (2016). Validitas Eksperimen. Buletin Psikologi, 19(2), 70-80. https://doi.org/10.22146/bpsi.11558

Hayati, E. N. (2013). Domestic violence against women in rural Indonesia Searching for multilevel prevention. In Umeå University Medical Dissertations (Issue 1617).

Heise, L. (2011). What Works to Prevent Partner Violence? An Evidence Overview. December. Ilyas, R. (2017). Zikir dan Ketenangan Jiwa: Telaah atas Pemikiran Al-Ghazali. Mawaizh: Jurnal Dakwah Dan Pengembangan Sosial Dan Kemanusiaan, 8(1), 90-106.

Imam, A., Mohammed, U., \& Moses Abanyam, C. (2014). On Consistency and Limitation of paired t-test, Sign and Wilcoxon Sign Rank Test. IOSR Journal of Mathematics, 10(1), 01-06. https://doi.org/10.9790/5728-10140106

John P. Wilson, \& Moran, T. A. (1998). Psychological Trauma : Posttraumatic Stress Disorder and Spirituality. Journal of Psychology and Theology, 26(2), 168-178.

KARAKAŞ, A. C., \& Geçimli, G. (2017). The Effect of Istighfar on State and Trait Anxiety. International Journal of Psychology and Educational Studies, 4(3), 73-79. https://doi.org/10.17220/ijpes.2017.03.008

Karni, A. (2014). Konseling dan Psikoterapi. Jurnal Ilmiah Syiar, 14(1), 225.

Komarudin, D., \& Halim, I. A. (2021). Peranan Terapi Spiritual Terhadap Penyembuhan Adiksi Narkoba. Syifa Al-Qulub, 5(2), 155-168.

Komnas Perempuan. (2019). Korban Bersuara, Data Bicara Sahkan RUU Penghapusan Kekerasan Seksual sebagai Wujud Komitmen Negara: Catatan Kekerasan terhadap Perempuan. Catatan Tahunan Tentang Kekerasan Terhadap Perempuan, 123.

Komnas Perempuan. (2020). Kekerasan meningkat: Kebijakan penghapusan kekerasan seksual untuk membangun ruang aman bagi perempuan dan anak perempuan. Catahu: Catatan 
Tahunan Tentang Kekerasan Terhadap Perempuan, 1-109.

Lebron McBride, J., \& Armstrong, G. (1995). The spiritual dynamics of chronic post traumatic stress disorder. Journal of Religion and Health, 34(1), 5-16. https://doi.org/10.1007/BF02248634

Levy, Y., \& Ellis, T. J. (2011). A guide for novice researchers on experimental and quasiexperimental studies in information systems research. Interdisciplinary Journal of Information, Knowledge, and Management, 6(January), 151-161. https://doi.org/10.28945/1373

Magezi, V., \& Manda, C. (2016). The use of spiritual resources to cope with trauma in daily existence. In Die Skriflig/In Luce Verbi, 50(1). https://doi.org/10.4102/ids.v50i1.2145

Maisah, M., \& SS, Y. (2016). Dampak Psikologis Korban Kekerasan Dalam Rumah Tangga Di Kota Jambi. ESENSIA: Jurnal Ilmu-Ilmu Ushuluddin, 17(2), 265. https://doi.org/10.14421/esensia.v17i2.1292

Manumpahi, E., Goni, S. Y. V. I., \& Pongoh, H. W. (2016). Kajian Kekerasan Dalam Rumah Tangga Terhadap Psikologi Anak Di Desa Soakonora Kecamatan Jailolo Kabupaten Halmahera Barat. Acta Diurna, V(1).

Mardiyati, I. (2015). Dampak Trauma Kekerasan dalam Rumah Tangga Terhadap Perkembangan Psikis Anak. Raheema, 2(1), 29-38. https://doi.org/10.24260/raheema.v2i1.166

Maslim, R. (2001). Diagnosis Gangguan Jiwa Rujukan Ringkas dari PPDGJ-III. PT. Nuh Jaya.

McLean, C. P., \& Foa, E. B. (2011). Prolonged exposure therapy for post-traumatic stress disorder: A review of evidence and dissemination. Expert Review of Neurotherapeutics, 11(8), 1151-1163. https://doi.org/10.1586/ern.11.94

Meichenbaum, D., \& Emeritus, D. (2008). Trauma, spirituality and recovery: Toward a spiritually-integrated psychotherapy. Www.Melissainstitute.Org, 519, 1-39.

Mohd Rozali, S., \& Muhammad Nubli, A. W. (2013). A Pilot Study of the Effect of Zikir on the Performance Psychology Using Heart Rate Variability (HRV). 4th International Graduate Conference on Engineering, Science \& Huminities (IGCESH ), 2-5. http://umpir.ump.edu.my/3548/\%5Cnhttp://umpir.ump.edu.my/3548/1/igcesh2013paper_(406).pdf

Muhajarah, K. (2016). Kekerasan Terhadap Perempuan dalam Rumah Tangga. Sawwa, 11(2), $127-146$.

Mulyanti, M., \& Massuhartono, M. (2018). Terapi Religi Melalui Dzikir Pada Penderita Gangguan Jiwa. JIGC (Journal of Islamic Guidance and Counseling), 2(2), 201-214. https://doi.org/10.30631/jigc.v2i2.17

Muslaini, R., \& Sofia, N. (2020). Efektivitas Terapi Zikir terhadap Post Traumatic Stress Disorder ( PTSD ) pada Penyintas Tsunami Palu Pendahulua n. 3(2), 123-134.

Muzayanah, U. (2016). Kekerasan Dalam Rumah Tangga Dan Peran Lembaga Agama Di Banyumas Jawa Tengah. Smart, 2(2), 199. https://doi.org/10.18784/smart.v2i2.319

Najati, M. . (2004). Al-Qur'an dan Ilmu Jiwa. Pustaka Pelajar.

Nashori, F. (2005). Hubungan Antara Kualitas dan Intensitas Dzikir Dengan Kelapangdadaan Mahasiswa. Millah, 5(1), 121-136. https://doi.org/10.20885/millah.vol5.iss1.art9

Nathanson, A. M., Shorey, R. C., Tirone, V., \& Rhatigan, D. L. (2012). The Prevalence of Mental Health Disorders in a Community Sample of Female Victims of Intimate Partner Violence. Partner Abuse, 3(1), 59-75. https://doi.org/10.1891/1946-6560.3.1.59

Niewiadomska, I., Jurek, K., Chwaszcz, J., Wośko, P., \& Korżyńska-Piętas, M. (2021). Personal resources and spiritual change among participants' hostilities in ukraine: The mediating role of posttraumatic stress disorder and turn to religion. Religions, 12(3), 1- 
16. https://doi.org/10.3390/rel12030182

Nirwana, A., \& Surakarta, U. M. (2019). MUSIBAH DALAM PERSPEKTIF AL-QUR 'AN. November.

Pajević, I., Sinanović, O., \& Hasanović, M. (2017). Association of Islamic Prayer with Psychological Stability in Bosnian War Veterans. Journal of Religion and Health, 56(6), 2317-2329. https://doi.org/10.1007/s10943-017-0431-z

Rahmania, A. R., \& Moordiningsih, M. (2012). Pengaruh Eye Movement Desensitization and Reprocessing (Emdr) Dengan Teknik Stabilisasi Untuk Menurunkan Posttraumatic Stress Disorder (Ptsd). Jurnal Intervensi Psikologi (JIP), 4(2), 161-172. https://doi.org/10.20885/intervensipsikologi.vol4.iss2.art2

Razak, A. (2013). Terapi Spiritual Islami. Jurnal Dakwah Tabligh, 14(1), 141-151.

Reflio, R., Dewi, A. P., \& Utomo, W. (2016). Pengaruh Terapi Al Zikir terhadap Kualitas Tidur Lansia. Jurnal Online Mahasiswa, 70(4), 921-946.

Riyadi, S. (2020). PENINGKATAN KUALITAS TIDUR PADA LANSIA DENGAN TERAPI DZIKIR : LITERATURE REVIEW The Improvement of Sleep Quality in Elderly With Dzikir Therapy: Literature Review. 11(02), 218-225.

Sasmita, H., Yanti, N., Hendri, K., \& Astuti, V. W. (2021). Jurnal Aisyah: Jurnal Ilmu Kesehatan Progressive Muscle Relaxation and Dhikr on Reducing Post- Traumatic Stress Disorder in Earthquake Victims Progressive Muscle Relaxation dan Dzikir Terhadap. 6(2), 385-391. https://doi.org/10.30604/jika.v6i2.494

Schoonenboom, J., \& Johnson, R. B. (2017). Wie man ein Mixed Methods-Forschungs-Design konstruiert. Kolner Zeitschrift Fur Soziologie Und Sozialpsychologie, 69, 107-131. https://doi.org/10.1007/s11577-017-0454-1

Shihab, M. . (2018). Wawasan Al-Quran tentang Doa dan Zikir. PT Lentera.

Slater, C. L., Bordenave, J., \& Boyer, B. A. (2016). Comprehensive Guide to Post-Traumatic Stress Disorders. Comprehensive Guide to Post-Traumatic Stress Disorders. https://doi.org/10.1007/978-3-319-08359-9

Solichah, M. (2013). Asesment Post Traumatic Stress Disorder (Ptsd) Pada Perempuan Korban Perkosaan (Acquaintance Rape). HUMANITAS: Indonesian Psychological Journal, 10(1), 87. https://doi.org/10.26555/humanitas.v10i1.331

Sugiyono. (2019). Metode Penelitian Kuantitatif Kualitatif \& RND. Alfabeta.

Taylor, S., Thordarson, D. S., Fedoroff, I. C., Maxfield, L., Lovell, K., \& Ogrodniczuk, J. (2003). Comparative efficacy, speed, and adverse effects of three PTSD treatments: Exposure therapy, EMDR, and relaxation training. Journal of Consulting and Clinical Psychology, 71(2), 330-338. https://doi.org/10.1037/0022-006X.71.2.330

Uyun, Q., Jaufalaily, N., Witruk, E., \& Kurniawan, I. N. (2020). Effect of Islamic-based repentance therapy on the prevention of post-traumatic stress disorder (PTSD). Psikohumaniora: Jurnal Penelitian Psikologi, 5(2), 125-138. https://doi.org/10.21580/pjpp.v5i2.6505

Uyun, Q., Kurniawan, I. N., \& Jaufalaily, N. (2019). Repentance and seeking forgiveness: the effects of spiritual therapy based on Islamic tenets to improve mental health. Mental Health, Religion and Culture, 22(2), 185-194. https://doi.org/10.1080/13674676.2018.1514593

Varma, D., Chandra, P. S., Thomas, T., \& Carey, M. P. (2007). Intimate partner violence and sexual coercion among pregnant women in India: Relationship with depression and posttraumatic stress disorder. Journal of Affective Disorders, 102(1-3), 227-235. https://doi.org/10.1016/j.jad.2006.09.026

Watkins, L. E., Sprang, K. R., \& Rothbaum, B. O. (2018). Treating PTSD: A review of 
evidence-based psychotherapy interventions. Frontiers in Behavioral Neuroscience, 12(November), 1-9. https://doi.org/10.3389/fnbeh.2018.00258

Weathers, F. W., Litz, B. T., Keane, T. M., Palmieri, P. A., Marx, B. P., \& Schnurr, P. P. (2013). The PTSD Checklist for DSM-5 (PCL-5) - Standard [Measurement instrument]. In National Center for Posttraumatic Stress Disorder-Ptsd (Vol. 5, Issue April, p. 3). https://www.ptsd.va.gov/. https://www.ptsd.va.gov/professional/assessment/documents/PCL5_Standard_form.PDF

Weathers, Frank W., Marx, B. P., Friedman, M. J., \& Schnurr, P. P. (2014). Posttraumatic Stress Disorder in DSM-5: New Criteria, New Measures, and Implications for Assessment. Psychological Injury and Law, 7(2), 93-107. https://doi.org/10.1007/s12207-014-9191-1

Wulandari, E., \& Nashori, H. F. (2014). Pengaruh terapi zikir terhadap kesejahteraan psikologis pada lansia. Jurnal Intervensi Psikologi, 6(2), 235-250. 